\title{
Deteksi Fertilitas Telur Burung Lovebird Berbasis Smartphone
}

\author{
Anugerah satria putra pratama ${ }^{1}$, Moh. Abdullah Anshori ${ }^{2}$ Hadiwiyanto $^{3}$ \\ ${ }^{1,2}$ Program Studi Jaringan Telekomunikasi Digital, \\ Jurusan Teknik Elektro, Politeknik Negeri Malang, 65141 \\ ${ }^{3}$ Program Studi Teknik Telekomunikasi, \\ Jurusan Teknik Elektro, Politeknik Negeri Malang, 65141 \\ 1.dwikarahman31@gmail.com, ${ }^{2}$ abdullah.anshori@polinema.ac.id, ${ }^{3}$ hadiwiyatno@polinema.ac.id
}

\begin{abstract}
Birds are animals that are very much favored by the community. Currently, lovebirds is popular to be kept and even bred, because the cost of maintenance is cheap and the opportunity to raise it is very good and promising. So that many people are interested in pursuing lovebird livestock business even though breeding is neither easy nor difficult.

The reseach purpose was to create monitoring system for the quality of lovebird eggs to be declared hatchable and unable to hatch by utilizing conveyor machines, infrared sensors, LDR sensors and servo motors. All these components are connected to smartphone via mcu node. The captured data is sent to firebase and monitored on the smartphone. The data includes the number of fertile and infertile eggs, and the eggs resistance value scanned by the LDR sensor. The system implementation is done by placing sample of lovebird eggs on conveyor machine and then testing it one by one, then the resistance value is displayed on the smartphone, then the average value is calculated, and the percentage of the sensor is successful in reading the egg condition.

The results of testing on lovebird eggs produced 2 conditions, fertile and infertilee. If the resistance value is $>5050 \mathrm{hm}$ then the egg is declared fertile and it's declared invert if resistance value is $<5050 \mathrm{hm}$. In distance testing, the most accurate distance is $1-24 \mathrm{~cm}$, the sensor cannot work accurately if the distance between eggs shorter, because the sensor takes time to return to the initial scan mode.
\end{abstract}

Keywords - Fertility Detection, Lovebird, Smartphone, LDR Sensor, MCU Node.

Abstrak-Burung merupakan hewan yang sangat banyak digemari oleh masyarakat. Saat ini burung yang ramai dipelihara bahkan dikembang biakkan adalah burung lovebird. karena biaya perawatannya murah dan peluang untuk beternak burung ini terbilang sangat bagus dan menjanjikan. Sehingga banyak orang tertarik untuk menekuni usaha ternak lovebird walaupun pengembangbiakannya susah-susah gampang.

Tujuan penelitian ini adalah membuat sistem monitoring kualitas telur burung lovebird untuk dinyatakan dapat menetas dan tidak dapat menetas dengan memanfaatkan mesin conveyor, sensor infrared, sensor LDR dan motor servo. Semua komponen tersebut terhubung ke smartphone melalui modul komunikasi node mcu. Data yang diambil dikirim ke firebase dan termonitoring di smartphone. Data tersebut meliputi jumlah telur fertile maupun infertile, dan nilai resistansi telur yang terscan oleh sensor LDR. Penerapan sistem dilakukan dengan cara menaruh sampel telur lovebird di mesin conveyor kemudian diuji satu persatu lalu nilai resistansinya dimunculkan di smartphone kemudian dihitung nilai rata-ratanya, serta menghitung persentase sensor berhasil membaca kondisi telur.

Hasil pengujian terhadap telur burung lovebird menghasilkan 2 kondisi yaitu fertile dan infertile. Jika nilai resistansi $>5050 h m$ maka telur dinyatakan fertile dan dinyatakan infertile jika nilai resistansi telur $<5050 \mathrm{hm}$. Pada pengujian jarak didapatkan jarak paling akurat pada 1-24 cm, semakin pendek jarak antar telur maka sensor tidak bisa bekerja secara akurat dikarenakan sensor membutuhkan waktu untuk kembali ke mode scan awal.

Kata kunci- Deteksi Fertilitas, Lovebird, Smartphone, Sensor LDR, Node MCU.

\section{PENDAHULUAN}

Pada saat ini peluang untuk beternak burung lovebird terbilang sangat bagus dan menjanjikan hingga banyak orang yang tertarik untuk menekuni atau menggeluti usaha ternak lovebird. Selain juga hobi beternak burung lovebird dari dulu hingga sekarang masih terus berkembang hingga tak pernah sepi peminatnya. Beternak burung lovebird salah satunya juga harus di perhatikan kondisi telurnya yang bisa menetas atau tidak, dikarenakan telur burung lovebird tidak semuanya akan menetas terkadang juga ada yang tidak menetas, untuk mengetahui telur yang layak menetas atau tidak biasanya para peternak masih kesulitan untuk mengetahuinya. Kondisi inilah yang sampai saat ini masih menjadi masalah untuk usahawan perkembangbiakan burung lovebird [2].
Selama ini ada beberapa metode manual yang digunakan untuk menegtahui kualitas telur lovebird tersebut antara lain dengan cara meneropong menggunakan senter di tempat yang gelap apabila telur yang di terawang itu bening berarti telur tersebut infertile atau sudah di pastikan tidak jadi atau tidak menetas sedangkan kalau yang diterawang itu gelap atau kelihatan urat-uratnya jadi telur tersebut fertile atau sudah di pastikan akan menetas. hal ini tentunya memakan waktu cukup lama karena dilakukan dengan mendeteksi telur satu persatu [2][3].

Dari permasalahan yang sudah dijelaskan di atas, perlu adanya sebuah sistem yang dapat membantu peternak burung lovebird lebih mudah untuk mengetahui kondisi telur tersebut maka dari itu muncullah ide untuk menyelesaikan sebuah 
sistem pendeteksi kualitas embrio burung lovebird berbasis smartphone, jadi pada alat ini nantinya diharapkan dapat menyelesaikan masalah diatas antara lain: 1.Bagaimana memilah telur burung lovebird yang fertile dan infertile; 2. Bagaimana cara menentukan jarak antar telur saat melakukan percobaan.

Berdasarkan beberapa masalah diatas terdapat penulisan untuk membatasi permasalah tersebut antara lain: 1. Node mcu sebagai komunikasi pengiriman data pada android; 2. Jarak keakurasian sensor ldr; 3. Android sebagai remot sistem dan penghitung.

Dan diharapkan setelah penelitian ini selesai nantinya dapat mencapai hasil atau tujuan yang diinginkan antara lain adalah: 1. Menghasilkan alat atau sistem yang dapat memilah telur lovebird yang fertile dan infertile secara cepat dan akurat, 2. Mempersingkat waktu pemilahan telur fertile dan infertile dari cara manual ke cara menggunakan conveyor dan sensor ldr ini, 3. Menghasilkan aplikasi android yang dapat memonitoring hasil pemilahan telur dan mudah di oprasikan oleh para peternak.

Serta ada beberapa manfaat unuk kedepannya setelah penelitian ini, berguna bagi para pengguna terutama peternak burung lovebird untuk dapat memilah telur fertile maupun infertile secara cepat selain itu menjadikan solusi juga bagi para peternak burung lovebird tentunya untuk bagaimana cara membedakan telur fertile dan infertile dengan bantuan sensor ldr dan yang terakhir selain simple juga pengoprasiannya mudah dengan bantuan smartphone sebagai tempat memonitoring jumlah telur fertile, infertile dan nilai resistansi telur tersebut.

\section{METODE}

\section{A. Prosedur Pengoperasian}

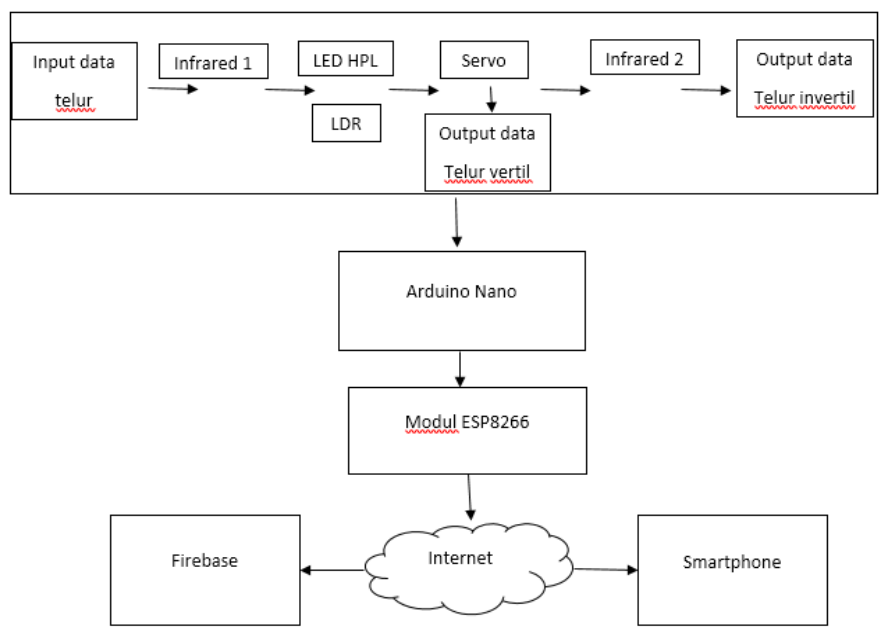

Gambar 1. Blok diagram perencanaan.

Berdasarkan blok diagram perencanaan dapat dijelaskan sebagai berikut:

Langkah pertama yang dilakukan menaruh telur pada mesin conveyor proses berikutnya telur terscan oleh sensor infrared untuk menandai bahwa data +1 juga bisa sebagai tanda telur akan mulai melalui tahap scan. Berikutnya telur melalui scan sensor ldr dan disorot oleh led supaya sensor ldr dapat membaca kondisi telur dan menghasilkan kondisi fertile atau infertile proses berikutnya telur akan dipilah oleh motor servo jika telur fertile maka servo on bila telur infertile maka servo off kemudian pengolahan data yang terjadi pada mesin conveyor tadi akan terkirim dan tersimpan di firebase dan dalam waktu bersamaan data tersebut juga akan terkirim atau termonitoring di aplikasi android.

\section{B. Perencanaan Komunikasi}

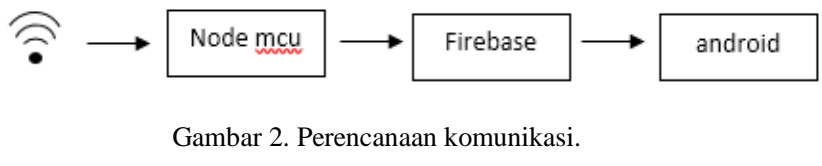

Jadi jaringan wifi/hotspot akan terkoneksi oleh node mcu lalu data yang sudah didapat akan terkirim dan tersimpan pada firebase dan secara bersamaan juga akan tampil secara realtime pada smartphone user.

\section{Diagram Alir Sistem}

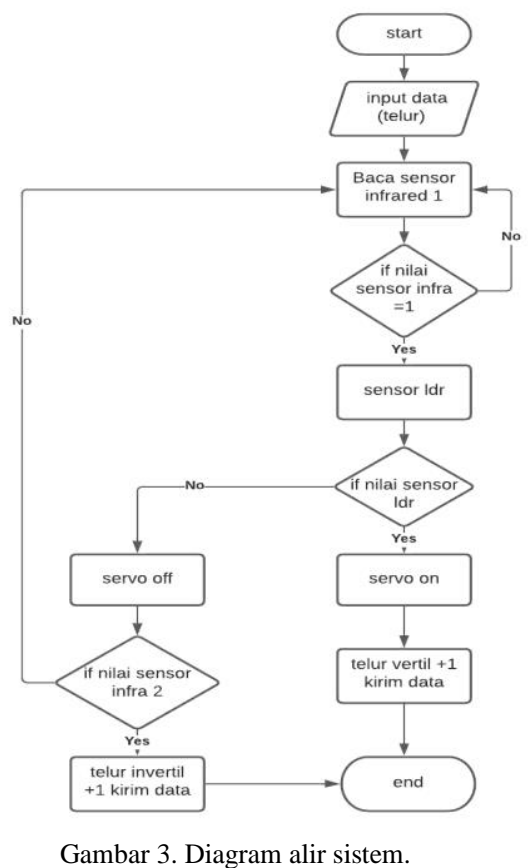

1. Langkah pertama yang dilakukan input data atau menaruh telur pada conveyor

2. Lalu sensor infrared akan membaca ya klo ada telur yang melewatinya dan tidak jika tadak ada telur yang melewatinya.

3. Kemudian baca sensor Ldr jika nilai sensor ldr $>505 \Omega$ maka servo on dan jika nilai sensor ldr $<505 \Omega$ maka servo off .

4. Setelah servo on terjadi pengiriman data telur fertile +1 selesai.

5. Jika servo off telur akan kembali melewati sensor infrared 2 sebagai penanda telur keluar jika iya maka akan terjadi pengiriman data infertile +1 , jika tidak maka akan kembali ke baca sensor 1 . 


\section{Kondisi telur lovebird}

Pada gambar ini merupakan kondisi telur lovebird mulai dari hari pertama sampai hari 28 dimana telur akan menetas.jadi telur lovebird bisa di cek kondisi vertil invertilnya yaitu minimal di umur 1 minggu - umur 2 minggu ini dimana umur telur lovebird paling akurat untuk bisa di cek kondisinya dengan alat ini.

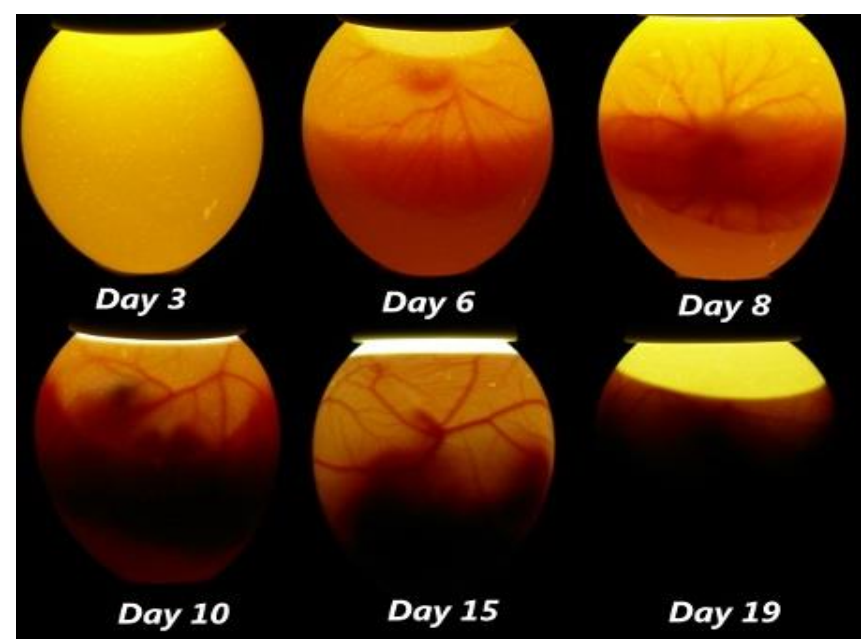

Gambar 4. Kondisi telur lovebird.

TABEL I

PENGUKURAN SENSOR PADA TELUR

\begin{tabular}{cc}
\hline Kondisi telur & Nilai Resistansi \\
\hline Vertil (isi) & $>505 \Omega$ \\
\hline Invertil (kosong) & $<505 \Omega$ \\
\hline
\end{tabular}

\section{HASIL DAN PEMBAHASAN}

Berikut merupakan aplikasi yang digunakan untuk memonitoring hasil yang meliputi jumlah telur fertile dan infertile, serta nilai resistansi. Kita juga dapat mereset data bila akan mengulang untuk pengambilan dan juga terdapat fitur untuk menyalakan dan mematikan mesin conveyor.

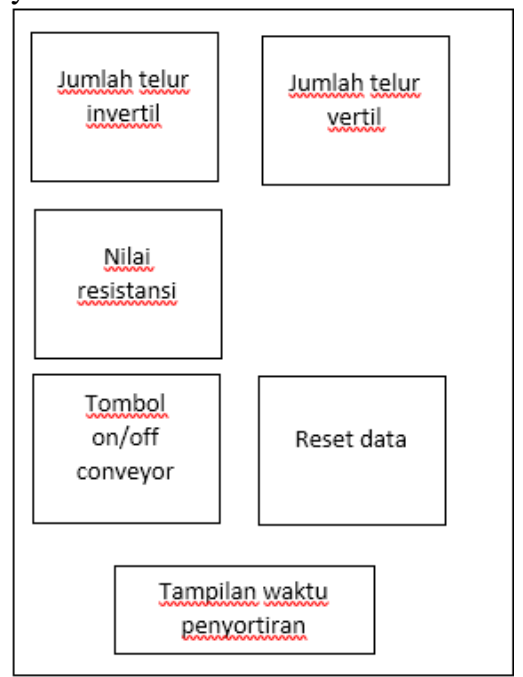

Gambar 5. Desain perancangan aplikasi.

\section{A. Jaringan wifi/hotspot}

Sebelum melakukan percobaan maka pastikan alat sudah tersambung dengan wifi/hotspot yang sudah terseting pada node mcu berupa username dan juga passwordnya. Setelah wifi/hotspot terseting pada node mcu maka nantinya waktu juga akan menyesuaikan sama pada smartphone contoh pengcodingan pada gambar berikut:

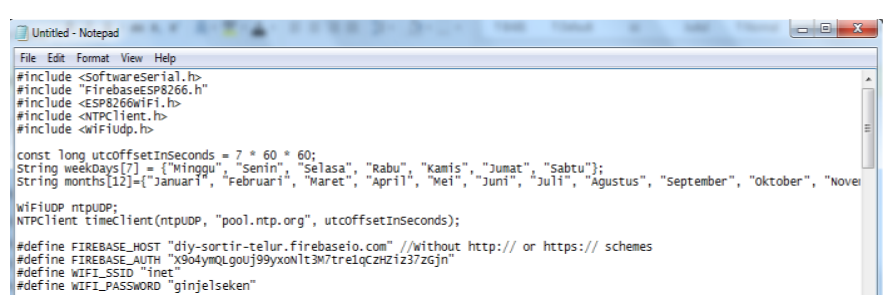

Gambar 6. Pengkodingan pada node mcu.

\section{B. Firebase dan android}

Setelah proses penyetingan wifi/hotspot pada node mcu maka selanjutnya dilakukan pengambilan data. Data yang sudah diambil selanjutanya akan terkirim pada firebase secara realtime.
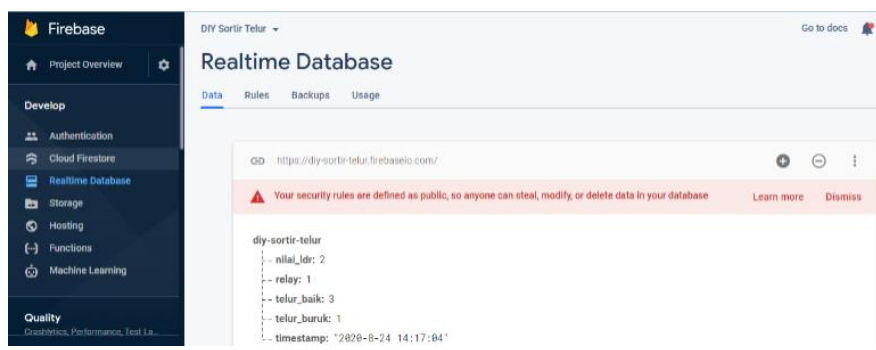

Gambar 7. Firebase

Seperti diketahui pada firebase tersebut terdapat tampilan yang sama seperti pada aplikasi android contohnya nilai ldr dimana ini menjadi tampilan unuk nilai resistansi pada telur, kemudian relay ini menunjukkan bahwa kondisi 0 maka mesin mati, jika 1 mesin hidup, telur baik dan telur buruk, untuk mengetahui jumlah telur fertile dan infertile dan yang terakhir terdapat tampilan untuk waktu pengambilan data. Jadi pada saat melakukan percobaan data di atas akan terus berubah seiring kita melakukan pengambilan data. 


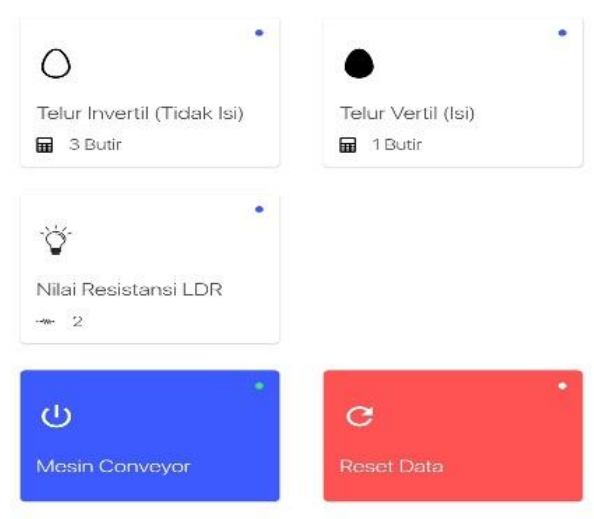

Terakhir Penyortiran Pada

Senin, 24 Agustus 2020

Gambar 8.Tampilan pada android.

\section{B. Contoh pengujian telur fertile}

Pada table di bawah ini merupakan contoh hasil pengujian telur fertile dimana menunjukkan nilai resistansi telur yang berhasil terbaca oleh sensor ldr dan tidak terbaca dikarenakan kondisi embrio telur yang belum sepenuhnya menutupi dalam telur lalu nilai resistansi dirata-rata dengan rumus jumlah resistansi yang sesuai dibagi banyaknya percobaan keseluruhan begitupun yang tidak sesuai resistansi tidak sesuai dibagi banyaknya percobaan.

TABEL 1I

PENGUJIAN TELUR FERTILE

\begin{tabular}{|c|c|c|c|}
\hline NO & SESUAI & TIDAK & RESISTANSI ( $(\Omega)$ \\
\hline 1 & $\sqrt{ }$ & & 755 \\
\hline 2 & $\sqrt{ }$ & & 713 \\
\hline 3 & $\sqrt{ }$ & & 869 \\
\hline 4 & & $x$ & 166 \\
\hline 5 & & $x$ & 160 \\
\hline 6 & & $x$ & 190 \\
\hline
\end{tabular}

\section{Contoh pengujian telur infertile}

Pada table di bawah ini kurang lebih sama penjelasannya seperti table 1 cuman yang memedakannya pada telur infertile yang terbaca fertile dikarenakan meskipun telur infertile kosong atau bening jika disenter tetapi telur pasti juga memiliki flek hitam entah dibagian kulitnya atau di dalamnya jadi yang terbaca fertile kemungkinan yang terkena sensor adalah bagian yang terdapat flek hitam.

TABEL III

PENGUJIAN TELUR INFERTILE

\begin{tabular}{cccc}
\hline NO & SESUAI & TIDAK & RESISTANSI ( $\mathbf{2})$ \\
\hline 1 & $\sqrt{ }$ & & 104 \\
\hline 2 & $\sqrt{ }$ & & 122 \\
\hline 3 & $\sqrt{ }$ & $\times$ & 648 \\
\hline 4 & & $\times$ & 798 \\
\hline 5 & & $\times$ & \\
\hline 6 & &
\end{tabular}

\section{E. Contoh pengujian telur fertile bebarengan}

Pada tabel di bawah ini merupakan contoh pengujian telur fertile bebarengan sebelumnya. Langkah ini sudah dilakukan uji coba jarak kekakurasian sensor ldr dengan dibagi menjadi 3 yaitu jarak dekat $1-8 \mathrm{~cm}$, sedang $1-16 \mathrm{~cm}$, jauh $1-24 \mathrm{~cm}$ dan mendapat kesimpulan bahwa pada jarak dekat sensor tidak dapat bekerja secara akurat contohnya telur pertama bisa terbaca akurat dan yang kedua tidak bisa dikarenakan sistem mendeteksi infertile dikarenakan sensor langsung berhadapan dengan cahaya dan kondisi sensor yang belum kembali pada mode scan, dan jarak paling optimalnya di jarak dengan range $1-24 \mathrm{~cm}$, pada jarak inilah sensor sudah dapat membaca telur 1 dan 2 secara akurat.

TABEL IV

PENGUJIAN TELUR FERTILE BEBARENGAN

\begin{tabular}{llllll}
\hline Percobaan & Telur 1 & Telur 2 & Resis 1 & Resis 2 & Jarak \\
\hline 1 & $\sqrt{ }$ & $\times$ & 791 & 94 & dekat \\
\hline 2 & $\sqrt{ }$ & $\times$ & 561 & 94 & dekat \\
\hline 1 & $\sqrt{ }$ & $\times$ & 867 & 89 & sedang \\
\hline 2 & $\sqrt{ }$ & $\times$ & 814 & 195 & sedang \\
\hline 1 & $\sqrt{ }$ & $\sqrt{ }$ & 521 & 624 & jauh \\
\hline 2 & $\sqrt{ }$ & $\sqrt{ }$ & 987 & 576 & jauh \\
\hline
\end{tabular}

\section{F. Contoh pengujian telur infertile bebarengan}

Pada contoh table di bawah ini kurang lebih sama seperti table III, yang membedakannya adalah kondisi telur yang di uji yaitu infertile, disini menggunakan metode yang sama pertama dibagi menjadi 3 jarak dekat, sedang, dan jauh tetapi telur infertile beda dengan fertile yang menyebabkan telur infertile terbaca fertile oleh sensor ialah kondisi cangkang telur biasanya terdapat kotoran atau flek yang menempel pada cangkang telur biasanya hal ini dapat dilihat jika menggunakan flash atau senter meskipun itu kecil tetapi jika posisi itu yang menghadap pada sensor artinya sensor membaca nilai fertile atau $>505 \Omega$.

TABEL V

PENGUJIAN TELUR INFERTILE BEBARENGAN

\begin{tabular}{llllll}
\hline Percobaan & Telur 1 & Telur 2 & Resis 1 & Resis 2 & jarak \\
\hline 1 & $\sqrt{ }$ & $\sqrt{ }$ & 101 & 141 & dekat \\
\hline 2 & $\times$ & $\sqrt{ }$ & 989 & 49 & dekat \\
\hline 1 & $\sqrt{ }$ & $\sqrt{ }$ & 122 & 118 & sedang \\
\hline 2 & $\sqrt{ }$ & $\sqrt{ }$ & 97 & 156 & sedang \\
\hline 1 & $\sqrt{ }$ & $\sqrt{ }$ & 76 & 91 & jauh \\
\hline 2 & $\sqrt{ }$ & $\sqrt{ }$ & 124 & 143 & jauh \\
\hline
\end{tabular}

\section{KESIMPULAN}

Berdasarkan perancangan alat dan hasil pengujian yang dilakukan pada penelitian dengan judul pendeteksi kualitas embrio telur burung lovebird berbasis smartphone dapat disimpulkan bahwa:

1. Dari pengujian terhadap telur burung lovebird menghasilkan 2 kondisi yaitu fertile dan infertile dimana jika nilai resistansi $>505 \Omega$ maka telur dinyatakan fertile dan jika nilai resistansi telur $<505$ $\Omega$ dinyatakan infertile.

2. Pengujian jarak keakurasian sensor dibagi menjadi 3 range dimana range pertama $1-8 \mathrm{~cm}$ yang ke dua 1-16 
Jurnal Jaringan Telekomunikasi, E-ISSN: 2654-6531, P-ISSN: 2407-0807 Vol. 11, No. 2 (2021) 81-85

$\mathrm{cm}$ dan yang ketiga 1-24 $\mathrm{cm}$,pada pengujian jarak ini didapatkan jarak paling akuratnya adalah $1-24 \mathrm{~cm}$ dimana semakin pendek jarak antara telur 1 dan 2 maka sensor tidak akan bisa bekerja secara akurat dikarenakan sensor membutuhkan waktu untuk kembali ke mode scan awal.

\section{REFERENSI}

[1] T. FERDYTIANTO, "Analisis pengaruh budidaya burung," 2013.

[2] R. Akbar and A. Sancoko, "Pendeteksi Embrio Dalam Telur Menggunakan Metode Image Processing," pp. 2-5, 2011.

[3] V. Wijayanti and A. Nugroho, "Alat Pendeteksi Telur Berbasis Mikrokontroler Pic16F84," J. Ilm. Go Infotech, vol. 21, no. 1, pp. 25-30, 2015. 